RESEARCH POINTERS

\title{
Risk of recurrence of prolonged pregnancy
}

\begin{abstract}
Paternal
genes as expressed by the fetus play a role in the timing of birth and in the risk of repeating a

Prolonged pregnancy-a pregnancy with a gestational length of 294 days or more-occurs in about $5 \%$ of all births. It is associated with a higher frequency of obstetric complications and perinatal morbidity, ${ }^{1}$ and little is known about its aetiology. ${ }^{2}$ We studied the risk of recurrence of prolonged pregnancy as a function of change in partner or change in social conditions.
\end{abstract} prolonged pregnancy

Danish Epidemiology Science Centre, University of Aarhus, DK-8000 Aarhus C, Denmark Annette Wind Olesen research fellow Olga Basso senior researcher Jørn Olsen professor

Correspondence to: A W Olesen a.w.olesen@ mail1.stofanet.dk

BMJ 2003;326:476

\section{Methods and results} registry on all women with a prolonged pregnancy in the first delivery and in a subsequent delivery, during $1980-94$, and a 5\% sample of all women with two or more pregnancies recorded in the period 1980-92 information on gestational age in the registry was residence stem from various population registers. birth to a singleton live infant recorded as post-term (gestational age 42 weeks or more) and a subsequent live infant. The term cohort included all women who had a first singleton live infant born at term (that is,
We obtained data recorded in the Danish medical birth (only the first two deliveries were used for analysis). The obtained from birth records that had been completed by midwives. Data on social status and municipality of

The post-term cohort included all women who gave gestational age 37-41 weeks) and a subsequent live infant. After excluding cases with missing information on gestational age (393 post-term cohort, 635 term cohort), paternity $(184,0)$, and stillborns $(300,177)$, we had 21746 sibling pairs in the post-term cohort and 7009 sibling pairs in the term cohort.

We studied the effect of changes in potential risk factors between pregnancies on post-term delivery with the computerised square dance design, ${ }^{3}$ which is based on Mackie's concept of causation. The basic idea is to study the effect of removing possible component causes from a causal field among the participants exposed to the variable being studied. The design is based on internal comparison within the two cohorts.

The risk of recurrence of post-term delivery was $19.9 \%$. It increased with increasing gestational age in the index birth to approximately $30 \%$ for a gestational age of 44 weeks. In the term cohort $7.7 \%$ were post-term in the subsequent birth.

Risk of post-term delivery in women giving birth in Denmark. Results are odds ratios (95\% confidence intervals)

\begin{tabular}{|c|c|c|c|c|}
\hline \multirow[b]{2}{*}{ Changes } & \multicolumn{2}{|c|}{ Post-term cohort ( $\geqslant 42$ weeks) } & \multicolumn{2}{|c|}{ Term cohort (37-41 weeks) } \\
\hline & Crude & Adjusted* & Crude & Adjusted* \\
\hline None & 1 & 1 & 1 & 1 \\
\hline Male partner & 0.74 & 0.73 (0.63 to 0.84$)$ & 0.93 & 0.99 (0.69 to 1.41$)$ \\
\hline Municipality & 0.93 & 0.96 (0.88 to 1.05$)$ & 0.89 & 0.83 (0.64 to 1.07$)$ \\
\hline \multicolumn{5}{|l|}{ Social status: } \\
\hline Decline & 0.91 & $0.92(0.80$ to 1.05$)$ & 0.80 & 0.78 (0.52 to 1.18$)$ \\
\hline Rise & 0.97 & 1.00 (0.91 to 1.09$)$ & 0.98 & 1.06 (0.81 to 1.38$)$ \\
\hline
\end{tabular}

${ }^{*}$ Adjusted for maternal age ( $\leqslant 19,20-24,25-29,30-34$, $\geqslant 35$ years), interpregnancy interval $(<1,1,2,3,4$, $5,6, \geqslant 7$ years), social status of the mother at index birth (low, middle, high), and county of residence at the birth of the subsequent child.
The risk of recurrence of post-term delivery was reduced to $15.4 \%$ when the first and second child had different fathers $(0.73,0.63$ to 0.84$)$ (table). Having a different father did not affect the risk of post-term delivery of the second child in the term cohort $(0.99$, 0.69 to 1.41 ). A change in municipality and social status had no impact on the risk of recurrence of prolonged pregnancy.

Length of pregnancy differed by more than one week in women who had changed partners, compared with those who had not (odds ratios 1.26, 1.13 to 1.41 in post-term cohort and 1.27, 1.04 to 1.54 in term cohort).

\section{Comment}

Women had a reduced risk of recurrent post-term delivery if they changed partner between pregnancies (table). We believe that this is a new observation. This result suggests that the timing of birth may, in part, be determined by paternal genes.

We have no information on induced labour before 42 weeks, but we have no reason to believe that labour was induced more frequently in women who had changed their partner between pregnancies. Induced labour probably contributes to misclassification in the analysis of risk of post-term delivery, but this is probably non-differential and underestimates the association with prolonged pregnancy. Furthermore, inducing labour before 42 weeks is unusual in Denmark. ${ }^{5}$ Misclassification of fathers-that is, a tendency not to report a new partner on the birth record-would probably lead to an underestimation of the partner effect since we expect this misclassification to be independent of gestational age.

We thank The National Board of Health and Statistics Denmark for supplying data.

Contributors: JO had the idea for the study and designed it; he also helped to revise the article. $\mathrm{OB}$ helped to analyse the data and revise the article; she also helped with the interpretation of the data. AWO carried out all the data analysis and wrote the first draft of the paper. AWO is the guarantor of the study.

Funding: This work was supported by Institute of Clinical Research, Odense University Hospital, Odense, Denmark; Institute of Epidemiology and Social Medicine, Aarhus University, Aarhus, Denmark; The Research Foundation in Funen County; and Director Jacob Madsen's and wife Olga Madsen's Foundation. The activities of the Danish Epidemiology Science Centre are funded by a grant from the Danish National Research Foundation.

Competing Interests: None declared.

1 Campbell MK, Ostbye T, Irgens LM. Post-term birth: risk factors and outcomes in a 10-year cohort of Norwegian births. Obstet Gynecol 1997;89: $543-8$

2 Shea KM, Wilcox AJ, Little RE. Postterm delivery: a challenge for epidemiologic research. Epidemiology 1998;9:199-204.

3 Olsen J, Schmidt MM, Christensen K. Evaluation of nature-nurture impact on reproductive health using half-siblings. Epidemiology 1997;8:6-11.

4 Mackie JL. The cement of the universe. A study of causation. Oxford: Oxford University Press, 1974

5 Stornes I. Behandling af overbaren graviditet i Danmark. En sporgeskemaundersogelse. [Management of prolonged pregnancy in Denmark. A questionnaire study.] Ugeskr Laeger 1996;158:422-4.

(Accepted 2 September 2002) 